\section{Political instability may be a contributor in the coming decade}

The next decade is likely to be a period of growing instability in the United States and western Europe, which could undermine the sort of scientific progress you describe in the Opinion collection of '2020 visions'.

Quantitative historical analysis reveals that complex human societies are affected by recurrent — and predictable - waves of political instability (P. Turchin and S. A. Nefedov Secular Cycles Princeton Univ. Press; 2009). In the United States, we have stagnating or declining real wages, a growing gap between rich and poor, overproduction of young graduates with advanced degrees, and exploding public debt. These seemingly disparate social indicators are actually related to each other dynamically. They all experienced turning points during the 1970s. Historically, such developments have served as leading indicators of looming political instability.

Very long 'secular cycles' interact with shorter-term processes. In the United States, 50-year instability spikes occurred around 1870, 1920 and 1970, so another could be due around 2020. We are also entering a dip in the so-called Kondratiev wave, which traces 40-60-year economic-growth cycles. This could mean that future recessions will be severe. In addition, the next decade will see a rapid growth in the number of people in their twenties, like the youth bulge that accompanied the turbulence of the 1960s and 1970s. All these cycles look set to peak in the years around 2020.

Records show that societies can avert disaster. We need to find ways to ameliorate the negative effects of globalization on people's well-being. Economic inequality, accompanied by burgeoning public debt, can be addressed by making tax rates more progressive. And we should not expand our system of higher education beyond the ability of the economy to absorb university graduates. An excess of young people with advanced degrees has been one of the chief causes of instability in the past.

Peter Turchin Department of Ecology and Evolutionary Biology,

University of Connecticut, Storrs,

Connecticut 06269, USA

e-mail: peter.turchin@uconn.edu

\section{Could a boom in technologies trap Feynman's simulator?}

I believe that quantum simulation is slated for a breakthrough by 2020. In a groundbreaking lecture (Intl J. Theor. Phys. 21, 467-488;

1982), Richard Feynman pointed out that large quantum systems are impossible to simulate with a classical computer. He proposed that they might instead be simulated with a quantummechanical machine - in short, a quantum simulator.

Some promising technologies have emerged, but verifying a quantum simulation is not straightforward. Do the results demonstrate properties of the simulated model, or are they due to unrelated features of the simulator? At first, this quandary seems insoluble, as the same complexity that drives one to attack the problem on a quantum simulator will thwart any attempt, whether analytical or on a regular computer, to prove the quantumsimulation result is correct.

But if the same physics models are simulated on different quantum simulators based on different technologies, it is quite likely that common features of all the results will be due to the quantumphysical model and not to the systematics of the simulators. Scientists and funders should therefore support development of as many technologies as possible. Dietrich Leibfried National Institute of Standards and Technology, Boulder, Colorado 80305, USA

e-mail: dil@boulder.nist.gov

\section{Expanded view of universities would be more realistic}

Tertiary education is poised for greater changes during the next decade than John Hennessey's vision implies (Nature 463, 28-29; 2010). The rising demand for university education in the developing world could affect universities in developed countries.

Western universities, for example, could help fill huge gaps in faculties in China, India and countries in southeast Asia, Africa and South America. Greater international cooperation and more study programmes abroad are likely to feature.

Distance learning could become more popular, particularly in remote areas. Open-course material, such as that pioneered by the Massachusetts Institute of Technology, might warrant further development. And modified programmes for professional degrees, such as a one-year Master of Business Administration, could become more widespread.

Siddharth Dasgupta NSF Center for Chemical Innovation, Caltech, Pasadena, California 91125, USA e-mail:sdg@caltech.edu

\section{Women: diversity among leaders is there if you look}

A disappointing myopia seems to have afflicted your '2020 visions', with just one female among the 20 contributors. This sends the wrong message at a time when women scientists are still striving for better representation.

Diversity among thought leaders is there if you look for it. You no longer have to look far among academics. Today, for example, women of vision are heads of the Massachusetts Institute of Technology; Harvard, Princeton and Brown universities; and the universities of Michigan, Pennsylvania and Cambridge.

Consider the Nobel prize. In 2009, it was awarded to five women (three of them scientists) and eight men, the narrowest gender gap since its inception.

The scientific community in 2020 should reflect the talent pipeline of 2010. Women are now well placed, if they stay the course, to enhance diversity in science. But they will need encouragement, support and opportunities if the barriers that have traditionally stymied diversity are to drop away. Nancy C. Andrews, Sally Kornbluth, Doug Stokke Duke University School of Medicine, Box 2927, Medical Center, Durham, North Carolina 27710, USA e-mail: nancy.andrews@duke.edu

\section{Women: why just one to represent half the workforce?}

In your prognostications about the future of science, you might have featured only women as authors, given that the ancient prophesying Sibyls were always female. However, there was just one woman among the twenty writers. We trust that ten years from now we shall not have to remind Nature that nearly half of working scientists (and Nature readers) are women.

Joan M. Herbers Association for Women in Science, 1442 Duke Street, Alexandria, Virginia 22314, USA e-mail: herbers.4@osu.edu

Readers are welcome to comment on the next 10 years for science, at go.nature.com/htW8uM 